Check for updates

Cite this: RSC Adv., 2018, 8, 32956

\title{
Waste solidification/stabilization of lead-zinc slag by utilizing fly ash based geopolymers
}

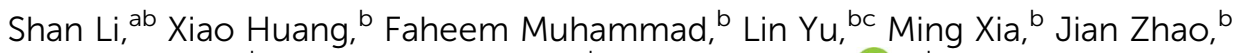 \\ Binquan Jiao, ${ }^{* a b c}$ YanChyuan Shiau*d and Dongwei Li (D) *ab
}

Solidification/stabilization (S/S) is recognized as an effective technology for solid waste treatment. In S/S, the application of geopolymers synthesized by industrial waste (rich in active silicon and aluminum) to immobilize hazardous waste is a research focus. In this article, a fly ash based geopolymer was used to immobilize lead-zinc slag containing $\mathrm{Pb}, \mathrm{Ni}, \mathrm{Zn}$ and $\mathrm{Mn}$. A fly ash based geopolymer with good mechanical strength was obtained through single factor experiments and the compressive strength of the geopolymer reached 29.72 MPa. The effects of immobilizing lead-zinc slag in the fly ash based geopolymer were discussed by means of compressive strength, leaching test and speciation analysis. The solidification/stabilization mechanism was further investigated using XRD, FTIR and SEM. The mechanical properties of the fly ash based geopolymer were negatively affected by addition of lead-zinc slag, and compressive strength decreased to $8.67 \mathrm{MPa}$ when $60 \%$ lead-zinc slag was added. The geopolymer has the ability to reduce toxicity of lead-zinc slag by immobilizing heavy metals ( $\mathrm{Pb}, \mathrm{Ni}, \mathrm{Zn}$ and $\mathrm{Mn}$ ), but the ability was not unlimited. The migration of heavy metals to residual form indicates that heavy metals may either be bonded into the geopolymer matrix via the $\mathrm{T}-\mathrm{O}$ bond $(\mathrm{T}=\mathrm{Si}, \mathrm{Al}$ ) or captured in framework cavities to maintain the charge balance. The $\mathrm{NASH}\left(\mathrm{Na}_{2} \mathrm{O}-\mathrm{Al}_{2} \mathrm{O}_{3}-\mathrm{SiO}_{2}-\mathrm{H}_{2} \mathrm{O}\right)$ gel structure observed by XRD, FTIR and SEM can physically encapsulate the contaminants during geopolymerization. It is finally concluded that heavy metals were immobilized in the fly ash based geopolymer through a combination of chemical bonding and physical encapsulation.

Received 7th August 2018

Accepted 6th September 2018

DOI: $10.1039 / \mathrm{c} 8 \mathrm{ra06634e}$

rsc.li/rsc-advances

\section{Introduction}

Waste management is a major challenge for global environmental protection. With the rapid development of industrialization, large amount of solid wastes were produced and most of them were not effectively treated. Lead-zinc slag is a solid waste obtained during smelting of lead and zinc ore that usually contains multiple heavy metals ( $\mathrm{Pb}, \mathrm{Zn}, \mathrm{Ni}, \mathrm{Mn})$. Lead-zinc slag stacked in the open air will not only result in serious environment pollution, but is also a threat to human health owing to the migration of toxic heavy metals under the action of rain leaching/wind erosion. ${ }^{1}$ How to effectively dispose of lead-zinc slag is the main purpose of this research.

Stabilization/solidification $(\mathrm{S} / \mathrm{S})$ is a successful application for preventing the migration of heavy metals. It was firstly used

${ }^{a}$ State Key Laboratory for Coal Mine Disaster Dynamics and Control, Chongqing University, Chongqing 400044, P. R. China. E-mail: litonwei@cqu.edu. cn; j.binquan@cqu.edu.cn

${ }^{b}$ College of Resource and Environmental Science, Chongqing University, Chongqing, 400044, China

${ }^{c}$ City College of Science and Technology, Chongqing University, Chongqing, 400044, China

${ }^{d}$ Dept. of Construction Management, Chung Hua University. No. 707, Wufu Rd., Sec. 2, Hsinchu 30012, Taiwan. E-mail: ycshiau@chu.edu.tw to treat nuclear waste in the 1950s and was then widely applied to treat hazardous waste in the early 1970 s. S/S has been identified by the US EPA as the Best Demonstrated Available Technology for 57 regulated hazardous waste ${ }^{2}$ and it is one of most frequently selected technologies for source control treatment projects in the US, being used in $23 \%$ of projects (both in situ and ex situ) between 1982 and 2005. Ordinary Portland Cement (OPC) was commonly used as the primary binder in $\mathrm{S} / \mathrm{S}$ at the beginning. More recently, application of geopolymers instead of OPC has become more popular. Compared with OPC, geopolymers have the characteristics of low energy consumption, low cost, early strength, fast hardening, good volume stability, corrosion and fire resistance. ${ }^{3}$

Geopolymers are a product of aluminosilicate materials activated by alkali solutions with a three-dimensional network structure mainly composed of $\left[\mathrm{SiO}_{4}\right]$ and $\left[\mathrm{AlO}_{4}\right]$. Davidovits ${ }^{4}$ suggested a chemical formula for geopolymers of $\mathrm{M}_{n}\left\{-\left(\mathrm{SiO}_{2}\right) \mathrm{z}\right.$ $\left.\mathrm{AlO}_{2}\right\}_{n} \cdot w \mathrm{H}_{2} \mathrm{O}$, where $\mathrm{M}$ is an alkali metal or metal cation (such as $\mathrm{Na}^{+}, \mathrm{K}^{+}$or $\left.\mathrm{Ca}^{2+}\right), n$ is the polymerization degree, and $w$ is the water content. Generally, the mechanism for geopolymerization includes the following stages: (i) dissolution of aluminosilicate components in strongly alkaline solution, (ii) formation of oligomers species as geopolymers precursors, (iii) polycondensation of the oligomers to form a three-dimension 
aluminosilicate framework and (iv) bonding undissolved solid particles into the framework and hardening into a final solid geopolymer structure. ${ }^{5}$ The alkali metal cation plays a major role of charge balancing during geopolymerization and different cations can be expected to influence the geopolymer structure. ${ }^{6,7}$

In this paper, fly ash was used as the material to synthesize the geopolymer. Fly ash is a solid waste from power plants; its main components (as oxides) include $\mathrm{SiO}_{2}, \mathrm{Al}_{2} \mathrm{O}_{3}, \mathrm{Fe}_{2} \mathrm{O}_{3}$ and $\mathrm{CaO}$. Compared to OPC, fly ash based geopolymers have improved physical and chemical properties, such as high compressive strength, durability and low permeability. ${ }^{8}$ The properties favor the use of geopolymers as solidification systems for toxic heavy metals. Related research ${ }^{9}$ has shown that the compressive strength of fly ash based geopolymer activated by sodium silicate reached $62.2 \mathrm{MPa}$ at 28 days. Little change in geopolymer structure was observed when $\mathrm{Cr}^{6+}, \mathrm{Cd}^{2+}$ and $\mathrm{Pb}^{2+}$ were added at $0.5 \%$. The immobilization of $\mathrm{Cr}^{6+}, \mathrm{Cd}^{2+}$ and $\mathrm{Pb}^{2+}$ was based on the chemical binding into the geopolymer gel or into the aluminosilicate phases. The leaching rate of metal ions significantly depended on the characteristics of the heavy metals and leaching solutions. Leaching in $\mathrm{H}_{2} \mathrm{SO}_{4}$ $(\mathrm{pH}=1)$ solution gave a higher rate of metal release than $\mathrm{MgSO}_{4}$ at $5 \mathrm{wt} \%$. Xu et al. ${ }^{10}$ found that heavy metals $\left(\mathrm{Cu}^{2+}, \mathrm{Cd}^{2+}, \mathrm{Cr}^{3+}\right.$ and $\mathrm{Pb}^{2+}$ ) can be effectively immobilized into the fly ash based geopolymer matrix at the same time. The concentration of the alkali activator was an important factor for the immobilization efficiency. The compressive strengths of geopolymers were improved by the addition ( $0.1 \%$ mass) of metal ions except for $\mathrm{Cr}^{3+}$. Moreover, the leaching behaviors of different heavy metals can influence each other. It confirmed that immobilization efficiencies of $\mathrm{Pb}^{2+}$ and $\mathrm{Cr}^{3+}$ were better than $\mathrm{Cu}^{2+}$ and $\mathrm{Cd}^{2+}$. Nikolic et al. ${ }^{11}$ also proposed that reactivity of fly ash was a key factor determining geopolymer mechanical and immobilization properties. The effectiveness of immobilizing $\mathrm{Cr}^{6+}$ by fly ash geopolymer depended on the fly ash characteristics, geopolymer synthesis conditions and concentration of $\mathrm{Cr}$ added. In another study, ${ }^{12}$ fly ash was firstly mechanically and then alkali activated at room temperature to immobilize $\mathrm{Pb}^{2+}$. Mechanical activation of fly ash led to a significant increase in compressive strength and reduced $\mathrm{Pb}^{2+}$ leaching from the geopolymer. $\mathrm{A}$ small increase in compressive strength was observed when $0.5 \% \mathrm{~Pb}^{2+}$ was added. Similarly, the research ${ }^{13}$ discussed $\mathrm{Pb}$ as $\mathrm{PbO}, \mathrm{PbSO}_{4}$ and $\mathrm{PbS}$ solidified by fly ash geopolymer; the $\mathrm{Pb}$ is converted to an amorphous form under alkali conditions and participates in the formation of the geopolymer network. Immobilization of $\mathrm{Pb}$ relies on chemical bonding and physical encapsulation.

Both fly ash and lead-zinc slag are industrial solid wastes. In this work, we used fly ash based geopolymer to solidify leadzinc slag (containing heavy metals) in order to achieve the goal of waste disposal. The geopolymer was prepared through single factor experiments. After that, different proportions of leadzinc slag were introduced into geopolymer matrix. Compressive strength, leaching test and speciation analysis of solidified bodies were used to discuss the solidification mechanism. Furthermore, X-ray diffraction (XRD), Fourier transform infrared spectroscopy (FTIR) and scanning electron microscopy (SEM) were conducted to support chemical and physical characteristics analysis.

\section{Materials and methods}

\subsection{Materials}

In the current experiment, fly ash (FA) was obtained from Chongqing, China. Lead-zinc slag (LZS) was collected from Yunnan, China. LZS was dried at $60{ }^{\circ} \mathrm{C}$, then ground by ball milling for $24 \mathrm{~h}$ and passed through a 200-mesh sieve. Sodium hydroxide $(\mathrm{NaOH})$ and sodium silicate $\left(\mathrm{Na}_{2} \mathrm{O} \cdot n \mathrm{SiO}_{2}, n=1\right.$; $21.53 \% \mathrm{Na}_{2} \mathrm{O}, 20.83 \% \mathrm{SiO}_{2}$ ) were used as alkali activators. All the reagents were analytical grade. Deionized water was used throughout the experiment.

The chemical components of FA and LZS as oxides were analyzed by X-ray fluorescence (XRF, Shimadzu, Japan) and the results are shown in Table 1. The main components of FA are $\mathrm{SiO}_{2}$ and $\mathrm{Al}_{2} \mathrm{O}_{3}$, which account for $76.95 \%$. The main components in LZS are $\mathrm{SiO}_{2}, \mathrm{Fe}_{2} \mathrm{O}_{3}$ and $\mathrm{CaO}$, accounting for $72.88 \%$. Moreover, $\mathrm{PbO}, \mathrm{NiO}, \mathrm{ZnO}$ and $\mathrm{MnO}$ have also been detected in LZS, and the contents of $\mathrm{ZnO}$ and $\mathrm{MnO}$ are much higher than those of $\mathrm{PbO}$ and NiO.

\subsection{Methods}

2.2.1 Geopolymer preparation. Geopolymer samples were prepared by using a single factor experiment. The factors include activators, liquid to solid ratio and curing temperature, and the details are given in Table 3 (Section 3.1). The alkali activator was prepared by mixing $\mathrm{NaOH}$ and $\mathrm{Na}_{2} \mathrm{SiO}_{3}$. They were firstly dissolved in deionized water and then stirred thoroughly with FA until a dense paste was achieved. The paste was filled into a mould $(20 \mathrm{~mm} \times 20 \mathrm{~mm} \times 20 \mathrm{~mm})$ and vibrated to make it compact. After curing at different temperatures for $24 \mathrm{~h}$, all samples were demoulded and continually cured at room temperature until $28 \mathrm{~d}$.

2.2.2 Compressive strength measurement. The compressive strength of the samples was measured on a universal testing machine (AGN-250, Shimadzu, Japan) at speed of 1

Table 1 The chemical components of LZS and FA (mass, \%) ${ }^{a}$

\begin{tabular}{lrl}
\hline Oxide & LZS & FA \\
\hline $\mathrm{SiO}_{2}$ & 30.67 & 49.74 \\
$\mathrm{Fe}_{2} \mathrm{O}_{3}$ & 29.73 & 10.78 \\
$\mathrm{CaO}$ & 12.48 & 3.38 \\
$\mathrm{Al}_{2} \mathrm{O}_{3}$ & 7.27 & 27.21 \\
$\mathrm{ZnO}$ & 6.39 & N.D. \\
$\mathrm{MgO}$ & 3.27 & 0.71 \\
$\mathrm{SO}_{3}$ & 3.06 & 1.41 \\
$\mathrm{MnO}$ & 2.97 & N.D. \\
$\mathrm{K}_{2} \mathrm{O}$ & 0.96 & 1.23 \\
$\mathrm{TiO}_{2}$ & 0.90 & 3.19 \\
$\mathrm{Na}_{2} \mathrm{O}$ & 0.72 & 1.46 \\
$\mathrm{P}_{2} \mathrm{O}_{5}$ & 0.15 & 0.32 \\
$\mathrm{PbO}^{\mathrm{NiO}}$ & 0.03 & N.D. \\
& 0.02 & N.D.
\end{tabular}

${ }^{a}$ N.D. Not detected. 
$\mathrm{mm} \min ^{-1}$. Three parallel samples were tested at the same time and the average value was taken.

2.2.3 Leaching tests. Leaching tests were carried out according to Chinese Environmental Protection Standard GB 16889-2008. The leaching method in this standard was used to simulate the leaching process of industrial waste after entering into sanitary landfill. All samples were crushed into particles smaller than $9.5 \mathrm{~mm}$, and then stirred for $18 \pm 2 \mathrm{~h}$ with acetic acid solution at a $\mathrm{pH}$ of $2.64 \pm 0.05$ in sealed containers. The liquid to solid ratio was kept at 20 . The total lead $(\mathrm{Pb})$, total nickel (Ni), total zinc ( $\mathrm{Zn})$ and total manganese $(\mathrm{Mn})$ were determined by XRF analysis and the leaching concentrations were determined by atomic fluorescence spectrometry.

2.2.4 Speciation analysis. The chemical forms of heavy metals in the samples were evaluated by Tessier sequential extraction scheme. ${ }^{\mathbf{1 4}}$ Samples were dried and subsequently ground in an agate mortar. 1 gram of sample was used for the initial extraction. The scheme contains a five-step sequential extraction procedure and the details are shown in Table 2. The elements were detected by ICP-OES (Optima 8000, PerkinElmer, USA).

2.2.5 Characterization analysis. Mineral phases of samples were tested by X-ray diffraction (XRD-6000, Shimadzu, Japan) from $5^{\circ}$ to $90^{\circ} 2 \theta$ at a scan rate of $2^{\circ} \mathrm{min}^{-1}$ and infrared spectra curves in the range of $400-4000 \mathrm{~cm}^{-1}$ were recorded on a Nicolet is5 spectrometer (Thermo Fisher Scientific, USA) by using the $\mathrm{KBr}$ pellet technique. In addition, the microstructure was observed by scanning electron microscope (SEM, TESCAN, Czech).

\section{Results and discussion}

\subsection{Preparation of FA based geopolymers}

Compressive strengths of FA based geopolymers with different compositions and curing conditions were tested and results are presented in Table 3.

The effects of alkali activators on compressive strength are shown in samples A1-A4. $\mathrm{Na}_{2} \mathrm{SiO}_{3}$ and $\mathrm{NaOH}$ as alkali activators have a great effect on the structure and compressive strength of the geopolymers. ${ }^{15-17}$ During the depolymerization reaction, $\mathrm{OH}^{-}$ions provided from the alkali activators accelerate dissolution of the active $\mathrm{Si} / \mathrm{Al}$ components. The generated $\mathrm{Si}$ and $\mathrm{Al}$ tetrahedron with negative charge reacts with water and sodium ions to form NASH $\left(\mathrm{Na}_{2} \mathrm{O}-\mathrm{Al}_{2} \mathrm{O}_{3}-\mathrm{SiO}_{2}-\mathrm{H}_{2} \mathrm{O}\right)$ gel, which is beneficial to the mechanical properties of the geopolymer. At the same time, $\mathrm{Na}_{2} \mathrm{SiO}_{3}$ can provide more mechanical strength owing to its high viscosity, which can improve the interfacial properties and reduce porosity in the geopolymer matrix. ${ }^{18,19}$ When the ratio of $\mathrm{Na}_{2} \mathrm{SiO}_{3}$ and $\mathrm{NaOH}$ is $2 / 3$, the compressive strength of $\mathrm{A} 2$ reaches $18.69 \mathrm{MPa}$. Compared with $\mathrm{A} 2$, the compressive strength of A1 decreases to $15.93 \mathrm{MPa}$. Excessive hydroxide ions in A1 may delay the polycondensation, thus adversely affecting the final mechanical strength. ${ }^{20}$ A decrease in compressive strength can also be observed in A3 and A4. However, this is owing to the alkalinity of $\mathrm{Na}_{2} \mathrm{SiO}_{3}$ being relatively less than that of $\mathrm{NaOH}$; less hydroxide ions in the 
Table 3 Preparation and compressive strength of geopolymer products ${ }^{a}$

\begin{tabular}{|c|c|c|c|c|}
\hline Samples & Activators $\mathrm{Na}_{2} \mathrm{SiO}_{3}: \mathrm{NaOH}$ & Liquid : solid & Curing temperature $\left({ }^{\circ} \mathrm{C}\right)$ & Compressive strength (MPa) \\
\hline $\mathrm{A} 1$ & $1 / 4$ & 0.22 & 60 & 15.93 \\
\hline $\mathrm{A} 2$ & $2 / 3$ & 0.22 & 60 & 18.67 \\
\hline A4 & $4 / 1$ & 0.22 & 60 & 5.74 \\
\hline W1 & $2 / 3$ & 0.21 & 60 & 12.09 \\
\hline W2 & $2 / 3$ & 0.22 & 60 & 18.67 \\
\hline $\mathrm{T} 1$ & $2 / 3$ & 0.22 & 45 & 4.72 \\
\hline $\mathrm{T} 2$ & $2 / 3$ & 0.22 & 60 & 18.67 \\
\hline $\mathrm{T} 3$ & $2 / 3$ & 0.22 & 75 & 28.29 \\
\hline $\mathrm{T} 4$ & $2 / 3$ & 0.22 & 90 & 29.72 \\
\hline
\end{tabular}

geopolymer matrix reduces the dissolution of active $\mathrm{Si} / \mathrm{Al}$ components.

The compressive strengths of W1-W4 vary as the ratio of liquid to solid increased. Water takes part in dissolution, hydration and polycondensation reactions during geopolymerization. ${ }^{21,22}$ It should be mentioned that when the ratio of liquid to solid is less than 0.21 , the workability of the mixture is poor and the mixture cannot be stirred thoroughly. Sufficient water gives the geopolymer paste good fluidity and dissolved $\mathrm{Si}$ / Al components can be fully contacted and reacted with alkali metal cations, while water also causes a dilution effect and reduces the alkalinity of the reaction system. According to the processes of geopolymerization, as mentioned before, the participation of water will promote the depolymerization reaction, which is conducive to the dissolution and diffusion of $\mathrm{Si} / \mathrm{Al}$ components under alkaline conditions. In contrast, during the process of polycondensation, water as a product inhibits the condensation reaction and has an adverse effect on the mechanical properties of the final geopolymer matrix. Hence, optimum water content is important for good workability and smooth reactions. ${ }^{20}$

The curing temperature significantly influenced the final mechanical properties of the geopolymer. When the curing temperature is $45{ }^{\circ} \mathrm{C}$, the compressive strength of the geopolymer was just 4.72 $\mathrm{MPa}$. As the curing temperature increased to $60{ }^{\circ} \mathrm{C}, 75{ }^{\circ} \mathrm{C}$ and $90{ }^{\circ} \mathrm{C}$, the compressive strength reached 18.67 MPa, 28.29 MPa and 29.72 MPa, respectively. FA based geopolymers can be cured at room temperature, but compressive strength develops slowly. Based on the research by Leung, ${ }^{23}$ high temperature removed the water from the fresh geopolymer matrix causing the collapse of capillary pores with a denser structure. It seems that the increasing curing temperature can accelerate the progress of geopolymerization and has a positive effect on the mechanical properties of the geopolymer. Related research $^{24,25}$ has proved that a higher curing temperature increases the activation rate of FA and enhances the geotechnical characteristics of geopolymer products.

In summary, the geopolymer synthesized under the following conditions had the best mechanical compressive strength (29.72 $\mathrm{MPa})$ : ratio of $\mathrm{Na}_{2} \mathrm{SiO}_{3}$ to $\mathrm{NaOH}=2 / 3$, liquid to solid ratio $=0.22$ and curing temperature $=90{ }^{\circ} \mathrm{C}$. These three factors favor the durability and stability of the alkali activated FA based geopolymer, and a good foundation is created for further solidification of LZS.

\subsection{Solidification/stabilization of LZS}

In order to investigate solidification/stabilization of LZS by FA based geopolymer, LZS was introduced into the geopolymer matrix. In this part, geopolymer sample $\mathrm{T} 4$ with the best mechanical strength (29.72 MPa) was selected to solidify LZS. Different proportions (10-60\%) of FA were exchanged to LZS, as shown in Table 4, and the preparation processes of the solidified bodies are still the same as those described in Section 2.2.

Table 4 Preparation and compressive strength of solidified bodies

\begin{tabular}{|c|c|c|c|c|c|c|}
\hline FL10 & 90 & 10 & $2 / 3$ & 0.22 & 90 & 28.96 \\
\hline FL20 & 80 & 20 & & & & 26.62 \\
\hline FL50 & 50 & 50 & & & & 12.09 \\
\hline FL60 & 40 & 60 & & & & 8.67 \\
\hline
\end{tabular}


Table 5 Leaching data ${ }^{a}$

Leaching Concentration $\left(\mathrm{mg} \mathrm{L}^{-1}\right)$

\begin{tabular}{lllcl} 
Sample & $\mathrm{Pb}$ & $\mathrm{Ni}$ & $\mathrm{Zn}$ & $\mathrm{Mn}$ \\
\hline FL10 & N.D. & 0.184 & 93.17 & 38.85 \\
FL20 & 0.006 & 0.187 & 219.6 & 78.61 \\
FL30 & 0.101 & 0.205 & 320.4 & 120.8 \\
FL40 & 0.219 & 0.210 & 392.7 & 147.9 \\
FL50 & 0.328 & 0.212 & 425.4 & 155.9 \\
FL60 & 0.388 & 0.221 & 493.1 & 179.9 \\
LZS & 1.467 & 0.564 & 1289 & 621.5 \\
Limit in GB 16889-2008 & 0.25 & 0.50 & 100 & -
\end{tabular}

${ }^{a}$ N.D. Not detected.

3.2.1 Compressive strength. As shown in Table 4, the compressive strengths of solidified bodies (FL10-FL60) continuously decrease as addition of LZS increases. When addition of LZS is $10 \%$, the compressive strength of FL10 decreases to 28.96 MPa, which is only 0.76 MPa less than geopolymer T4. However, when addition of LZS is $60 \%$, the compressive strength of FL60 decreases sharply to $8.67 \mathrm{MPa}$. It is obvious

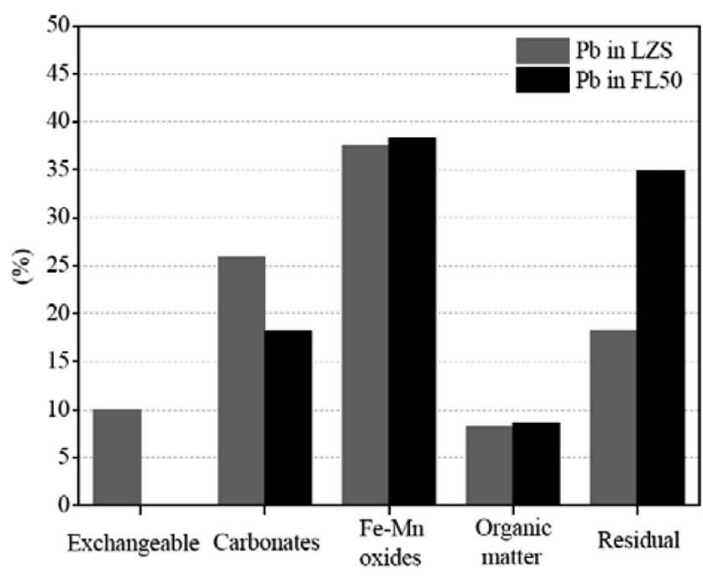

(a)

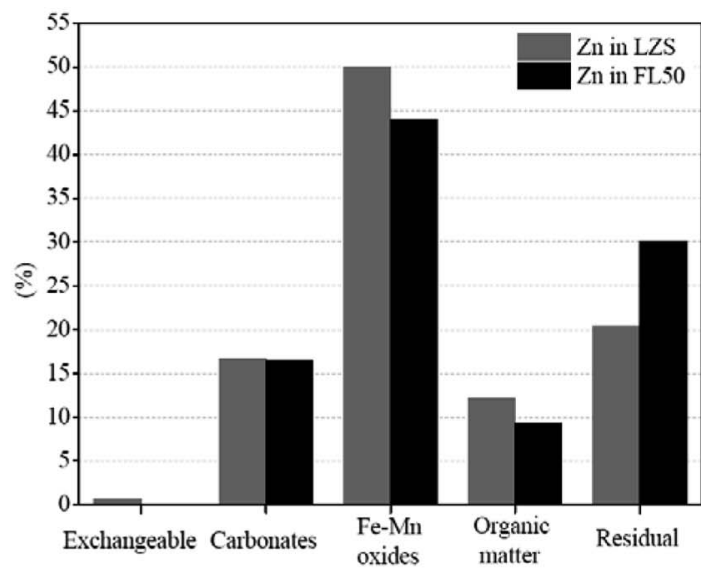

(c) that LZS has an adverse effect on the mechanical properties of FA-based geopolymers. From XRF analysis in Table 1, the components of $\mathrm{SiO}_{2}$ and $\mathrm{Al}_{2} \mathrm{O}_{3}$ are only $37.94 \%$ in LZS, while they are $76.95 \%$ in FA. It means that when more FA was exchanged for LZS, less active Si/Al components can participate in geopolymerization, directly leading to a decline in mechanical strength of solidified body.

3.2.2 Leaching tests. A leaching test is a usual method for evaluating the immobilization efficiencies of different heavy metals in any complex system. Many studies have explored the capacity of geopolymers to encapsulate or immobilize heavy metals and the leaching results showed varied immobilization efficiencies of different metals. ${ }^{\mathbf{1 0 , 2 6}}$

Leaching data are presented in Table 5. The leaching concentrations of $\mathrm{Pb}, \mathrm{Ni}, \mathrm{Zn}$ in LZS are $1.467 \mathrm{mg} \mathrm{L}^{-1}$, $0.564 \mathrm{mg} \mathrm{L}^{-1}$ and $1289 \mathrm{mg} \mathrm{L}^{-1}$, respectively, which are beyond the limits in GB 16889-2008. Although there is no limit on Mn in the standard, its solidification efficiency is also under discussion owing to its toxicity. According to the results of the leaching test, the toxicity of LZS can be reduced through immobilization by FA based geopolymer. However, the leaching concentrations of $\mathrm{Pb}, \mathrm{Ni}, \mathrm{Zn}, \mathrm{Mn}$ gradually increase with the

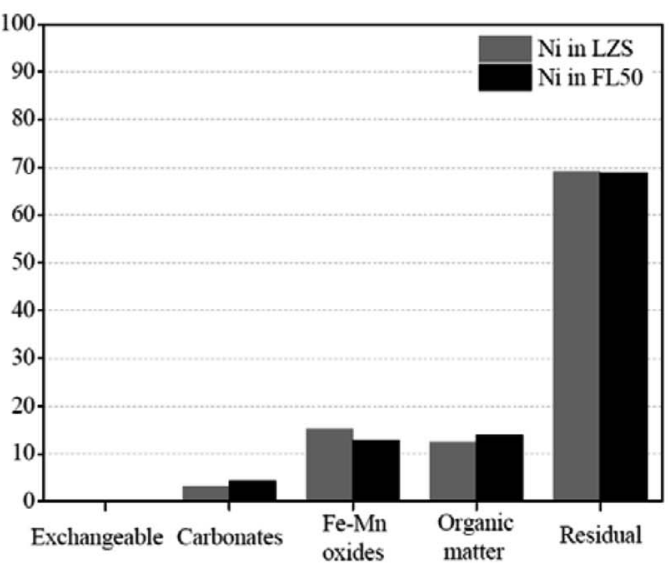

(b)

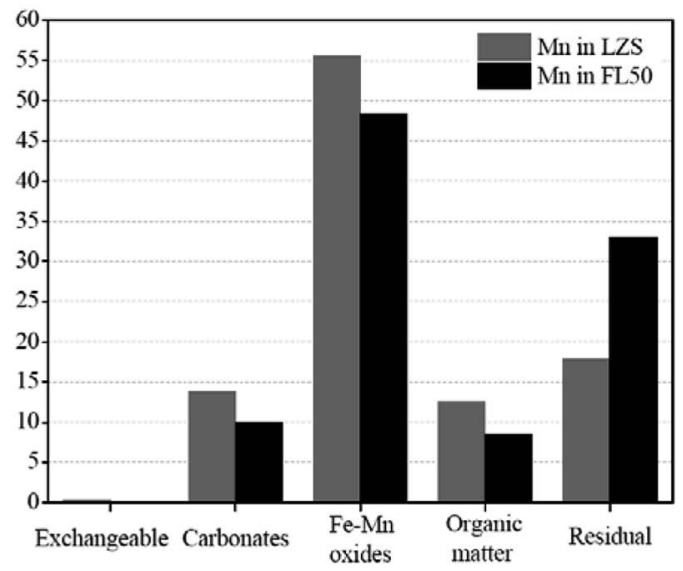

(d)

Fig. 1 Chemical forms of (a) Pb, (b) Ni, (c) Zn, and (d) Mn in LZS and FL50. 

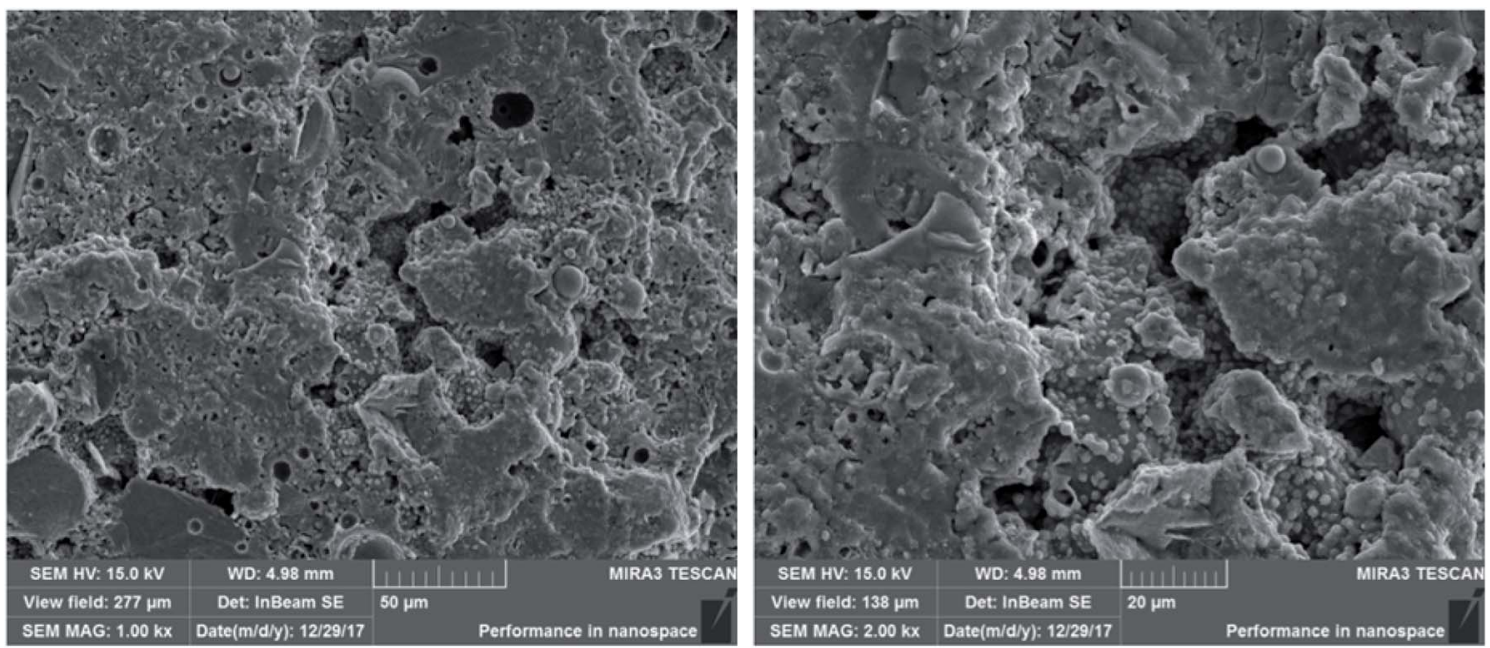

(a)
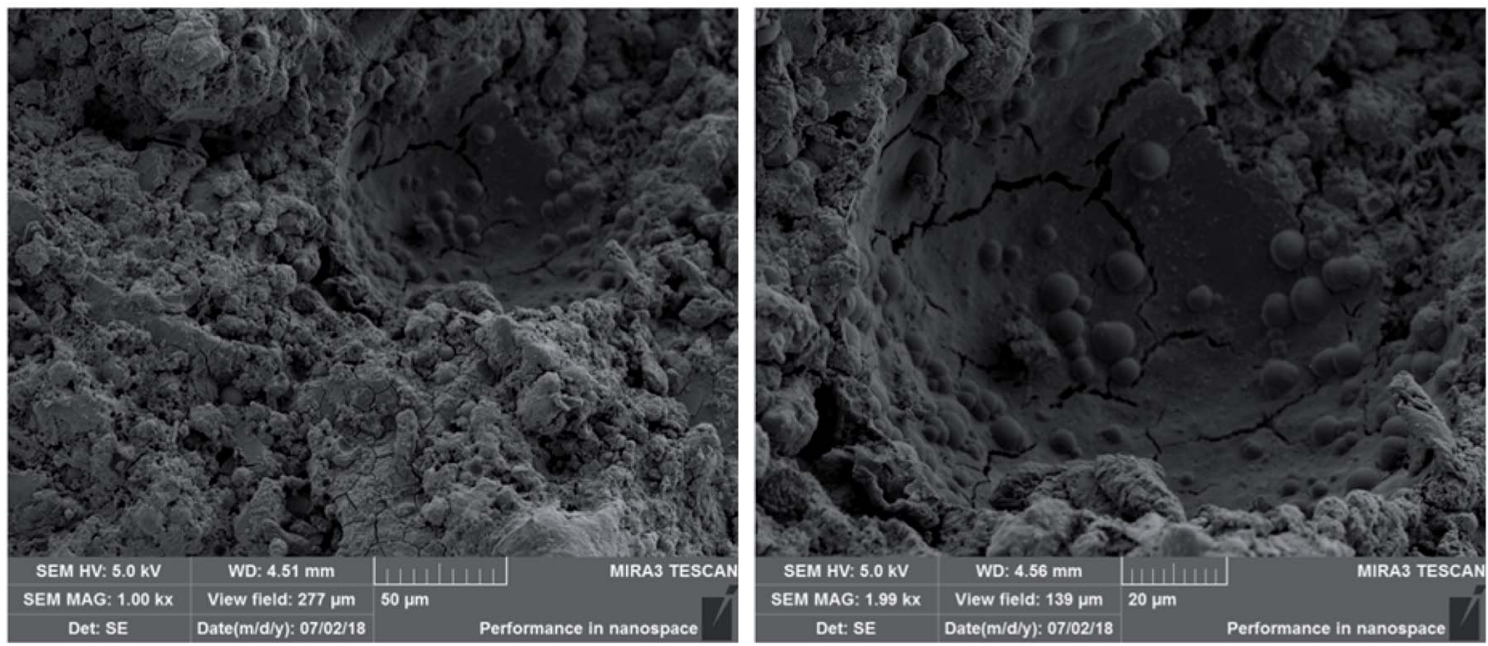

(b)

Fig. 2 SEM micrographs of (a) T4 and (b) FL50.

increase of LZS added in the geopolymer matrix. The leaching concentration of $\mathrm{Zn}$ exceeds the limit when addition of LZS is $10 \%$, and the leaching concentration of $\mathrm{Pb}$ exceeds the limit when addition of LZS is $50 \%$. It indicates that the geopolymer has the ability to immobilize heavy metals, but the ability is not unlimited.

Combined with compressive strength analysis of solidified bodies, high compressive strength means a denser structure, while the decreasing compressive strength will make it easier for corrosive acid to destroy the structure of geopolymer matrix and break chemical bonds, and increasing the possibility of metals being released. ${ }^{26}$ The solidified body FL10 (mixed with $90 \%$ FA and $10 \%$ LZS) has less reduction of compressive strength $(28.96 \mathrm{MPa})$ and the leaching concentrations of all heavy metals are below the limit in GB 16889-2008.

3.2.3 Speciation analysis. Five chemical forms of $\mathrm{Pb}, \mathrm{Zn}$, Mn, Ni in LZS and FL50 were tested and the results are shown in Fig. 1. For heavy metals, the bioactivities of exchangeable, carbonate, Fe-Mn oxides, organic matter and residual forms decrease in sequence. The first three forms are more likely to migrate through biochemical processes, resulting in higher risk of environmental pollution. In pure LZS, only exchangeable forms of $\mathrm{Pb}, \mathrm{Zn}$, and $\mathrm{Mn}$ are detected, and not $\mathrm{Ni}$. The exchangeable form of $\mathrm{Pb}$ is the highest and reaches $10.07 \%$, followed by $\mathrm{Zn}(0.67 \%)$ and $\mathrm{Mn}(0.32 \%)$. Carbonate forms of $\mathrm{Pb}$, $\mathrm{Zn}, \mathrm{Mn}$, and $\mathrm{Ni}$ reach $25.93 \%, 16.77 \%, 13.72 \%$ and $3.11 \%$, respectively. The Fe-Mn oxides of $\mathrm{Pb}, \mathrm{Zn}, \mathrm{Mn}$, and $\mathrm{Ni}$ reach $37.50 \%, 50.03 \%, 15.32 \%$ and $55.51 \%$, respectively.

In FL50, the exchangeable form of $\mathrm{Pb}$ almost disappears, and the carbonate form is decreased by $7.8 \%$, while the forms of $\mathrm{Fe}-$ Mn oxides, organic matters and residual are increased by $0.80 \%, 0.39 \%$ and $16.59 \%$, respectively. It is important to note that the migration of $\mathrm{Pb}$ to residual form indicates that $\mathrm{Pb}$ at least participates in the geopolymerization in chemical ways. That means metal ions of $\mathrm{Pb}$ may either be bonded into the geopolymer matrix via the bond of $\mathrm{T}-\mathrm{O}(\mathrm{T}=\mathrm{Si}, \mathrm{Al})$ or captured 


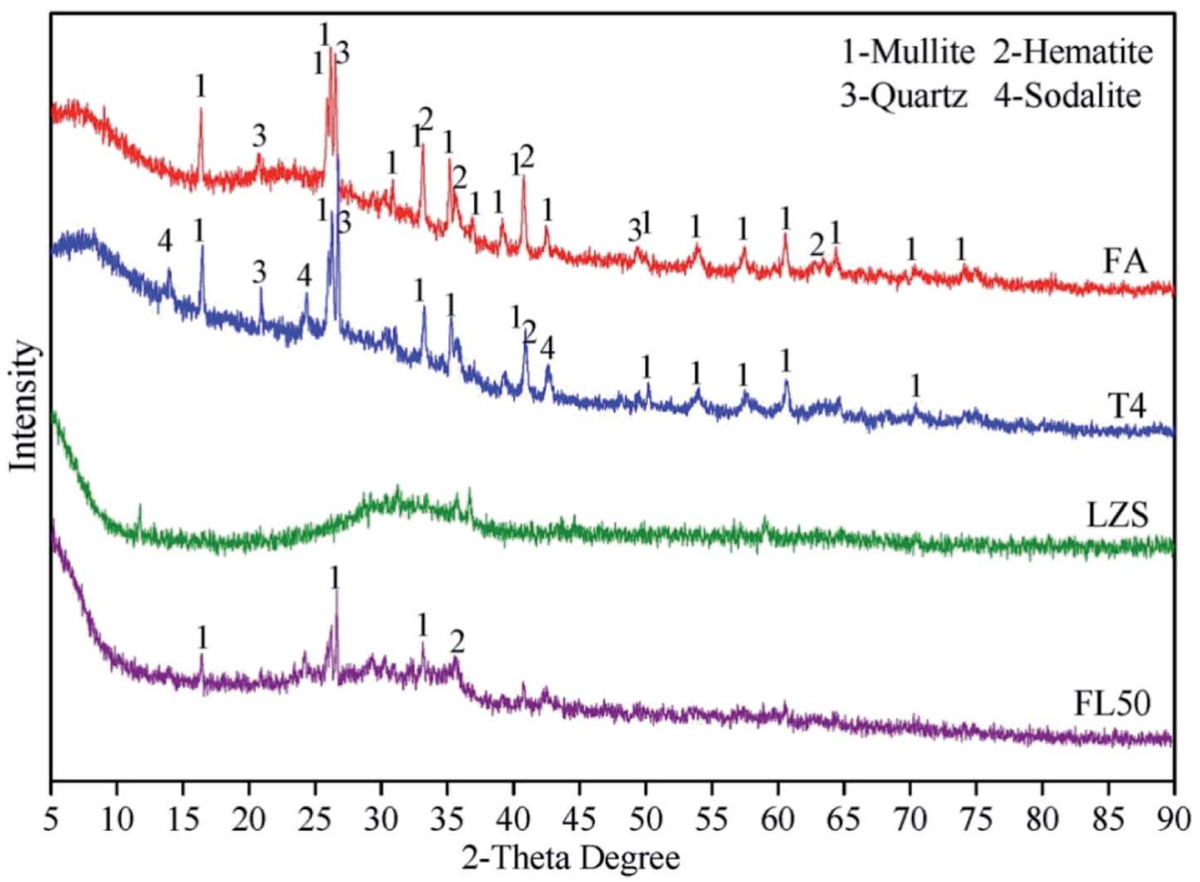

Fig. 3 XRD patterns of FA, T4, LZS and FL50.

in framework cavities instead of sodium ions to maintain charge balance. In this circumstance, $\mathrm{Pb}$ can be efficiently immobilized in the geopolymer matrix and maintain stability under corrosive acid attack, thus greatly reducing the possibility of being released into the external environment. A similar phenomenon is also observed with $\mathrm{Zn}$ and $\mathrm{Mn}$. The residual forms of $\mathrm{Zn}$ and $\mathrm{Mn}$ are increased by $9.76 \%$ and $15.13 \%$, respectively. It shows that when multiple heavy metals are introduced into the geopolymer matrix at the same time, the chemical immobilization effect can be carried out simultaneously. ${ }^{\mathbf{1 0}}$

In addition, owing to the low bioactivity of Ni itself in LZS, its chemical forms have changed little and the phenomenon of migration to residual form is not observed in FL50. Ni is more likely to be immobilized by physical encapsulation but not chemical ways in the geopolymer matrix.

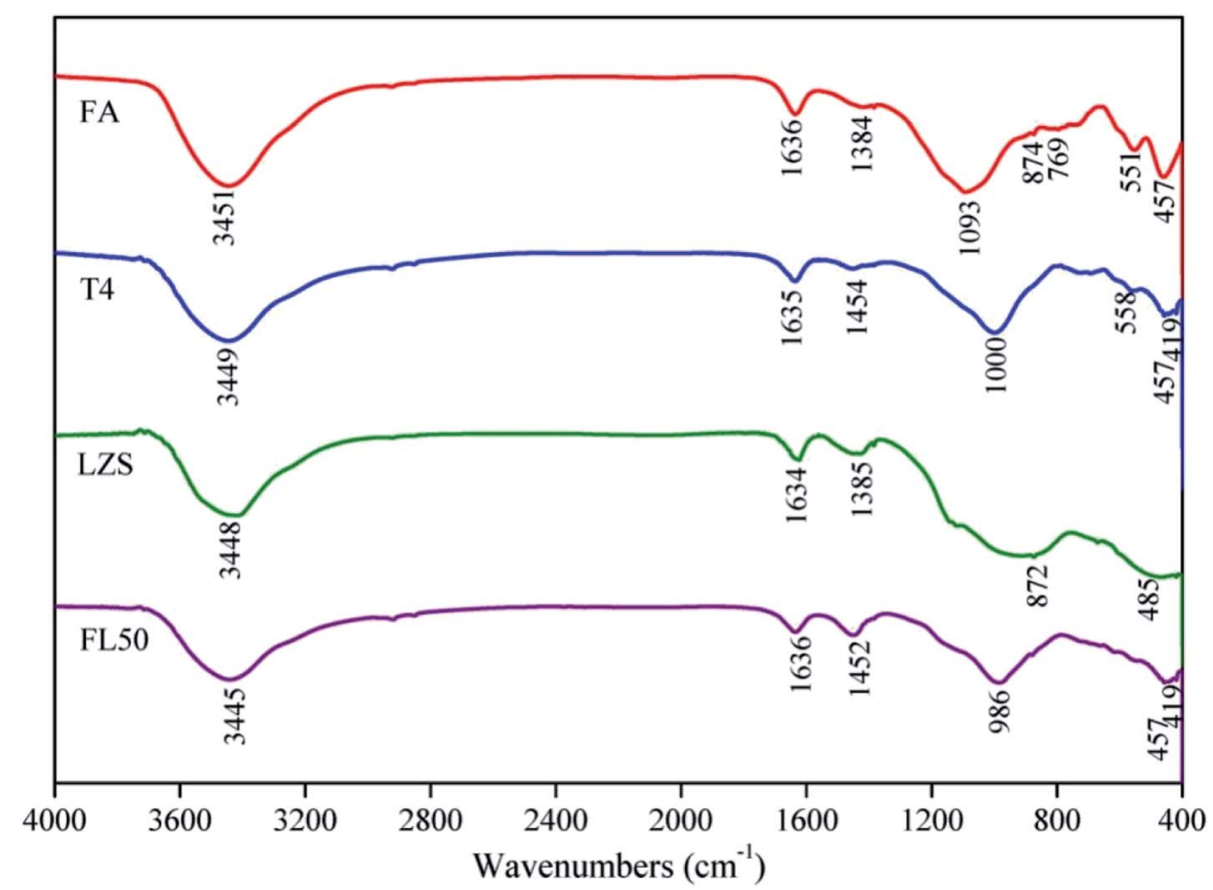

Fig. 4 FTIR spectra of FA, T4, LZS and FL50. 


\subsection{SEM analysis}

SEM micrographs of T4 and FL50 are shown in Fig. 2. In T4, the FA dissolved by alkali activator developed a dense gel structure in geopolymer matrix and some undissolved FA particles are trapped into the gel. The gel has a certain fluidity before hardening into a solid and can physically encapsulate contaminants.

The dissolved FA particles and gel-like structure are also observed in FL50. However, compared with T4, addition of LZS makes the structure become loose and porous. As discussed before, the loose and porous structure will make it easier for corrosive acid to destroy the geopolymer matrix and increase the possibility of metals being released.

\subsection{XRD analysis}

XRD patterns are shown in Fig. 3. Although fly ash is an essentially vitreous material (diffuse peaks recorded for $2 \theta=$ $20-35^{\circ}$ ), it also contains a series of crystalline phases, such as mullite, quartz and hematite. Those crystalline phases are detected in both FA and T4, signifying that they do not participate in the geopolymerization owing to their lowers activity. It has to be highlighted that the reduction of diffuse peaks $\left(20-35^{\circ}\right.$ $2 \theta$ ) in T4 is attributed to the formation of alkaline aluminosilicate gel. ${ }^{27-29}$ The new crystalline phase of sodalite $\left(\mathrm{Na}_{8} \mathrm{Al}_{6} \mathrm{Si}_{6}\right.$ $\mathrm{O}_{24}(\mathrm{OH})_{2}\left(\mathrm{H}_{2} \mathrm{O}\right)_{2}$, PDF 76-1639) observed in $\mathrm{T} 4$ testifies that sodium ions are involved in the geopolymerization. The dissolved active $\mathrm{Si} / \mathrm{Al}$ components react with the sodium ions to form amorphous NASH gel, and part of them as precursors transform into zeolite-like species.

The XRD pattern of LZS shows mainly amorphous phases. After being immobilized by the geopolymer, no new crystalline substances are detected in FL50. Different from sodium ions, heavy metals that participate in geopolymerization do not produce corresponding crystalline phases.

\subsection{FTIR analysis}

FTIR spectra curves of samples are shown in Fig. 4. Wavenumbers of $3200-3800 \mathrm{~cm}^{-1}$ and $1600-1700 \mathrm{~cm}^{-1}$ are characteristics of $\mathrm{H}-$ $\mathrm{OH}$, mainly representing $\mathrm{H}_{2} \mathrm{O}$ in all samples. The FTIR spectrum of FA mainly contains wide and intense bands associated with the internal vibrations in the $\mathrm{TO}_{4}$ tetrahedron $(\mathrm{T}=\mathrm{Al}, \mathrm{Si})$, the bands centered at $1093 \mathrm{~cm}^{-1}$ and $457 \mathrm{~cm}^{-1}$ are associated with $\mathrm{T}-\mathrm{O}$ bond asymmetric stretching vibrations and $\mathrm{T}-\mathrm{O}$ bond internal deformation vibrations, respectively. According to the previous research, ${ }^{30,31}$ the bands at $550-560 \mathrm{~cm}^{-1}$ and $780-790 \mathrm{~cm}^{-1}$ indicate the presence of mullite and quartz.

The absorbance in the $1200-900 \mathrm{~cm}^{-1}$ region corresponds to T-O bond asymmetric stretching vibrations. This "main band" located at $1093 \mathrm{~cm}^{-1}$ in FA shifts to higher wavenumbers of $1000 \mathrm{~cm}^{-1}$ in $\mathrm{T} 4$, indicating that sodium ions are involved in the geopolymerization and bonded into the geopolymer phase; this was also proved in the XRD analysis. El-Eswed et al. ${ }^{32}$ accurately explained this phenomenon: interaction of aluminosilicates with alkali resulted in the increase of the nonbridging oxygens $\left(\mathrm{Si}-\mathrm{O}-\mathrm{Na}^{+}, \mathrm{Al}-\mathrm{O}-\mathrm{Na}^{+}\right)$and this explanation will be accepted in this study. Based on this, the stability mechanism of heavy metals in the geopolymer can be deduced by coordination with nonbridging $\mathrm{Si}-\mathrm{O}^{-}$and $\mathrm{Al}-\mathrm{O}^{-}$. In FL50, addition of $\mathrm{LZS}$ reduces the band wavenumbers to $986 \mathrm{~cm}^{-1}$. It can thus be deduced that the heavy metals at least bonded into the geopolymer phase and this opinion was also proved by the other research. ${ }^{9}$

A peak at $1384 \mathrm{~cm}^{-1}$ corresponding to $\mathrm{NO}_{3}{ }^{-}$is observed in FA and LZS. ${ }^{33}$ Bonds located at $1454 \mathrm{~cm}^{-1}$ (S12) and $1452 \mathrm{~cm}^{-1}$ (FL50) corresponding to stretching vibrations of $\mathrm{O}-\mathrm{C}-\mathrm{O}$ indicate the presence of sodium bicarbonate, which is suggested to occur owing to atmospheric carbonation of the $\mathrm{NaOH}$ aqueous phase on the geopolymer matrix surface. ${ }^{19,34}$

\subsection{Mechanism analysis}

During geopolymerization, alkali activated $\mathrm{Si} / \mathrm{Al}$ components are dissolved into $\mathrm{Si} / \mathrm{Al}$ tetrahedral units with hydroxyl ions. To keep the charge balance, sodium ions are bonded with negatively charged Si/Al units and depolymerize into the formation of the amorphous NASH structure. The zeolite phase of sodalite is observed and sodium ions enter into its framework structure and form nonbridging oxygens $\left(\mathrm{Si}-\mathrm{O}-\mathrm{Na}^{+}, \mathrm{Al}-\mathrm{O}-\mathrm{Na}^{+}\right)$. In summary, the processes can be described by eqn (1) and (2) as follows:

$$
\left(\mathrm{Si}_{2} \mathrm{O}_{5}, \mathrm{Al}_{2} \mathrm{O}_{2}\right) n+n \mathrm{SiO}_{2}+n \mathrm{H}_{2} \mathrm{O} \stackrel{\mathrm{NaOH}, \mathrm{Na}_{2} \mathrm{SiO}_{3}}{\longrightarrow} n(\mathrm{OH})_{3}-\mathrm{Si}-\mathrm{O}-\stackrel{\stackrel{(-)}{\mathrm{Al}}-\mathrm{Si}-(\mathrm{OH})_{3}}{\mid}
$$

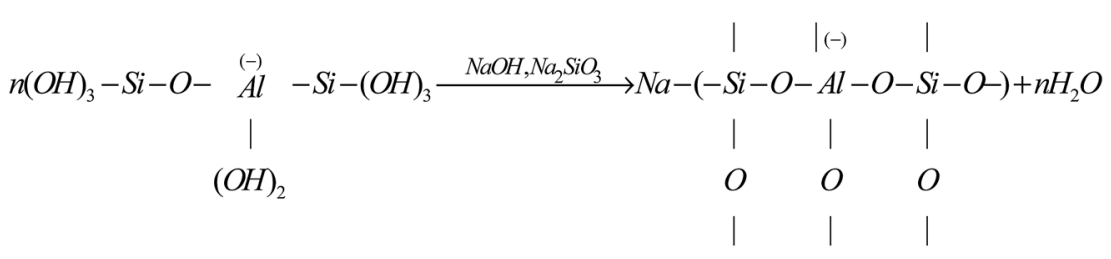


With regard to immobilization of heavy metals, no crystalline phases with heavy metals were detected. Heavy metals $\left(\mathrm{M}^{n+}\right.$, with high bioactivities) are at least bonded into the geopolymer phase through replacing the sodium ions to keep the charge balance and are stabilized by coordination with nonbridging $\mathrm{Si}-$ $\mathrm{O}^{-}$and $\mathrm{Al}-\mathrm{O}^{-}$, which is shown in eqn (3). Besides, physical encapsulation also plays a role in the immobilization process, which is determined by the durability and permeability of the geopolymer structure. If the geopolymer matrix is denser, it will be able to prevent leaching of metals. It is concluded that both chemical and physical immobilization are important for the leaching performance under aggressive conditions. contaminants and in this circumstance the dense structure can reduce the possibility of heavy metals being released.

\section{Conflicts of interest}

There are no conflicts of interest to declare.

\section{Acknowledgements}

This research did not receive any specific grants from funding agencies in the public, commercial, or not for profit sectors.

$$
n(\mathrm{OH})_{3}-\mathrm{Si}-\mathrm{O}-\stackrel{(-)}{\mathrm{Al}}-\mathrm{Si}-(\mathrm{OH})_{3} \frac{\mathrm{NaOH}_{2} \mathrm{Na}_{2} \mathrm{SiO}_{3}}{M^{m+}}\left(\mathrm{Na}^{+}, \mathrm{M}^{n+}\right)-\left(-\mathrm{Si}-\mathrm{O}-{ }_{(\rightarrow)} \mathrm{Al}-\mathrm{O}-\mathrm{Si}-\mathrm{O}-\right)+n \mathrm{H}_{2} \mathrm{O}
$$

\section{Conclusions}

Solid waste containing silicon and aluminum components has shown great potential for application in S/S. Utilizing a FA based geopolymer to solidify lead-zinc slag (containing heavy metals) can achieve the goal of waste disposal. Further improving the mechanical property and solidification efficiency of geopolymer is the focus of future research. In the current study, the following conclusions are drawn:

(i) Geopolymers synthesized from alkali activated FA show good mechanical properties, which are significantly influenced by the factors of alkali activator, water addition and curing temperature. Through single factor experiments, the compressive strength of geopolymer reached 29.72 MPa. During geopolymerization, the production of NASH gel provides mechanical strength to the geopolymer matrix.

(ii) The geopolymer has the ability to immobilize heavy metals and the toxicity of LZS can be reduced through immobilization, however, the ability is not unlimited. With increased contaminants added into the geopolymer, the mechanical properties of the geopolymer are negatively affected, and the leaching concentrations of heavy metals are also increased. The solidified body with $90 \%$ FA and $10 \%$ LZS has the potential for application in building materials.

(iii) Heavy metals are immobilized in the geopolymer matrix through a combination of chemical bonding and physical encapsulation. By chemical bonding, the heavy metals may either be bonded into the geopolymer matrix via coordination with nonbridging $\mathrm{Si}-\mathrm{O}^{-}$and $\mathrm{Al}-\mathrm{O}^{-}$or captured in framework cavities to maintain the charge balance. The phenomenon of migration to residual form testifies this opinion. Through physical encapsulation, the fluid gel before hardening into a solid can encapsulate

\section{References}

1 S. Mor, K. Ravindra, R. P. Dahiya and A. Chandra, Environ. Monit. Assess., 2006, 118, 435.

2 B. Batchelor, J. Waste Manage., 2006, 26, 689-698.

3 T. Bakharev, Cem. Concr. Res., 2006, 36, 1134-1147.

4 J. Davidovits, J. Therm. Anal. Calorim., 1991, 37, 1633-1656.

5 D. Panias, I. P. Giannopoulou and T. Perraki, Colloids Surf., A, 2007, 301, 246-254.

6 J. E. Oh, P. J. M. Monteiro, S. S. Jun, S. Choi and S. M. Clark, Cem. Concr. Res., 2010, 40, 189-196.

7 A. Fernández-Jiménez and A. Palomo, Cem. Concr. Res., 2005, 35, 1984-1992.

8 C. F. Pereira, Y. Luna, X. Querol, D. Antenucci and J. Vale, Fuel, 2009, 88, 1185-1193.

9 J. Zhang, J. L. Provis, D. Feng and J. S. van Deventer, J. Hazard. Mater., 2008, 157, 587-598.

10 J. Z. Xu, Y. L. Zhou, Q. Chang and H. Q. Qu, Mater. Lett., 2006, 60, 820-822.

11 V. Nikolić, M. Komljenović, N. Džunuzović, T. Ivanović and Z. Miladinović, Composites, Part B, 2017, 112, 213-223.

12 V. Nikolić, M. Komljenović, N. Marjanović, Z. Baščarević and R. Petrović, Ceram. Int., 2014, 40, 8479-8488.

13 B. Guo, D. A. Pan, B. Liu, A. A. Volinsky, M. Fincan, J. Du and S. Zhang, Constr. Build. Mater., 2017, 134, 123-130.

14 G. Rauret, Talanta, 1998, 46, 449.

15 A. Fernández-Jiménez, A. Palomo and M. Criado, Cem. Concr. Res., 2005, 35, 1204-1209.

16 U. Rattanasak and P. Chindaprasirt, Miner. Eng., 2009, 22, 1073-1078.

17 K. Somna, J. Chai, P. Kajitvichyanukul and P. Chindaprasirt, Fuel, 2011, 90, 2118-2124. 
18 A. R. Brough and A. Atkinson, Cem. Concr. Res., 2002, 32, 865-879.

19 M. Criado, A. Palomo and A. Fernández-Jiménez, Fuel, 2005, 84, 2048-2054.

20 Z. Zuhua, Y. Xiao, Z. Huajun and C. Yue, Appl. Clay Sci., 2009, 43, 218-223.

21 K. Sagoe-Crentsil and L. Weng, J. Mater. Sci., 2007, 42, 30073014.

22 L. Weng and K. Sagoe-Crentsil, J. Mater. Sci., 2007, 42, 29973006.

23 C. K. Y. Leung and T. Pheeraphan, Cem. Concr. Res., 1995, 25, 136-146.

24 A. Arulrajah, A. Mohammadinia, S. Horpibulsuk and W. Samingthong, Constr. Build. Mater., 2016, 127, 743-750.

25 A. Mohammadinia, A. Arulrajah, J. Sanjayan, M. M. Disfani, M. W. Bo and S. Darmawan, J. Mater. Civ. Eng., 2016, 28, 04016141.
26 J. G. S. V. Jaarsveld, J. S. J. V. Deventer and L. Lorenzen, Metall. Mater. Trans. B, 1998, 29, 283-291.

27 A. Fernández-Jiménez and A. Palomo, Fuel, 2003, 82, 22592265.

28 T. Bakharev, Cem. Concr. Res., 2005, 35, 1233-1246.

29 M. Criado, A. Fernández-Jiménez, A. G. de la Torre, M. A. G. Aranda and A. Palomo, Cem. Concr. Res., 2007, 37, 671-679.

30 A. Fernández-Jiménez and A. Palomo, Microporous Mesoporous Mater., 2005, 86, 207-214.

31 M. Criado, A. Fernández-Jiménez and A. Palomo, Microporous Mesoporous Mater., 2007, 106, 180-191.

32 B. I. El-Eswed, O. M. Aldagag and F. I. Khalili, Appl. Clay Sci., 2017, 140, 148-156.

33 W. K. W. Lee and J. S. J. V. Deventer, Cem. Concr. Res., 2002, 32, 577-584.

34 E. U. Haq, S. K. Padmanabhan and A. Licciulli, Constr. Build. Mater., 2014, 66, 781-786. 